www.jmscr.igmpublication.org

Impact Factor 5.84

Index Copernicus Value: 71.58

ISSN (e)-2347-176x ISSN (p) 2455-0450

crossref DOI: _https://dx.doi.org/10.18535/jmscr/v5i10.181

Journal Of Medical Science And Clinical Research

IGM Publication

An Official Publication of IGM Publication

\title{
Primary Neonatal Iliopsoas Abscess - A Rare Case Report
}

\author{
Authors \\ Dr Lokesh Reddy Chigicherla ${ }^{1}$, Dr Krishna Mohan Pottala ${ }^{2}$, Dr Deepthi Sriramineni ${ }^{3}$ \\ ${ }^{1}$ Consultant Radiologist, Vijaya Diagnostic Center KPHB, Hyderabad, India \\ ${ }^{2}$ Consultant Radiologist, Vijaya Diagnostic Center S.D Road, Secunderabad, India. \\ ${ }^{3}$ Consultant Radiologist, Vijaya Diagnostic Center KPHB, Hyderabad, India \\ Corresponding Author \\ Dr Lokesh Reddy Chigicherla \\ Plot.No-161, Madhavaram Nagar Colony,Near Star Kids School, Kukatpally, Hyderabad-500072. \\ Ph.No +917799190080, Email: lokeshreddychigi@gmail.com
}

\begin{tabular}{l} 
Abstract \\
We report a case of 27 days old male child with complaints of progressively increasing swelling in left \\
groin region extending up to left thigh. The child has been reffered to our center for an M.R.I scan. On \\
performing M.R.I scan a diagnosis of left ilopsoas muscle abscess has been offered. Only 14 cases have \\
been reported so far in the literature $(1$ \& 2$)$ We present this rare neonatal case of primary Iiopsoas \\
abscess and discuss clinical symptoms, etiologic agents, methods of diagnosis and therapy, and prognosis. \\
Keywords: Iliopsoas Abscess, Septic Arthritis, MRI Seqences, Extra Peritoneal Drainage. \\
\hline
\end{tabular}

\section{Case Report}

A 27 days old male neonate, with uneventfull pregnancy and normal vaginal delivery with birth weight of $2.5 \mathrm{kgs}$ came with complaints of progressively increasing swelling in left groin region extending up to left proximal thigh along with restricted movements of left hip joint and low grade fever.

Initially $\mathrm{x}$-ray pelvis has been done as a priliminary investigation by the clinician which was showing vague soft tissue opacity on left grion region with mild increase in left hip joint space compared to right hip joint. There was no bony abnormality noted.

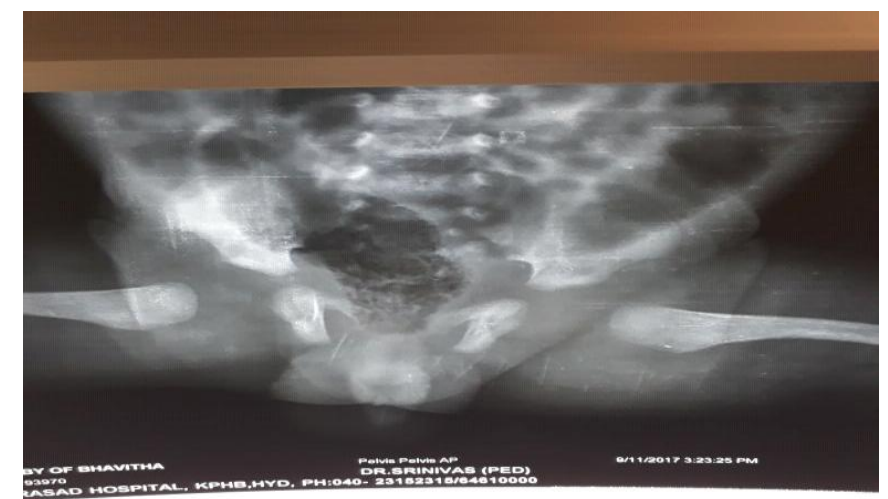

Routine Ultrasonography of the pelvis was done in the hospital which showed collection in the left groin involving left hip joint space and thigh regions. Clinician suspecting Left Hip joint septic arthritis correlating the ultrasonography findings and reffered for an M.R.I scan here in our center. 


\section{JMSCR Vol||05||Issue||10||Page 29549-29551||October}

M.R.I Findings : M.R.I scan was performed on Philips Ingenia 1.5 Tesla Machine. Sequences Performed are T1wieghted, T2 Weighted and STIR in Axial, Sagittal \& Coronal sections.

\section{STIR}
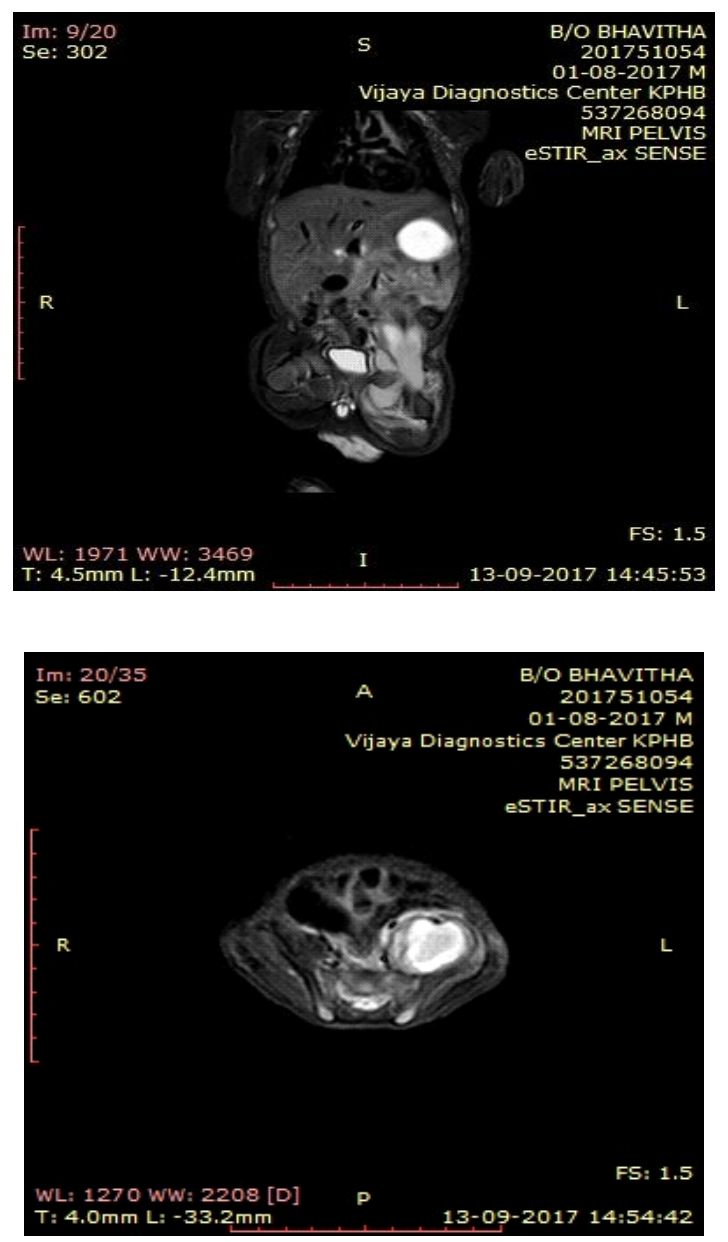

T2W

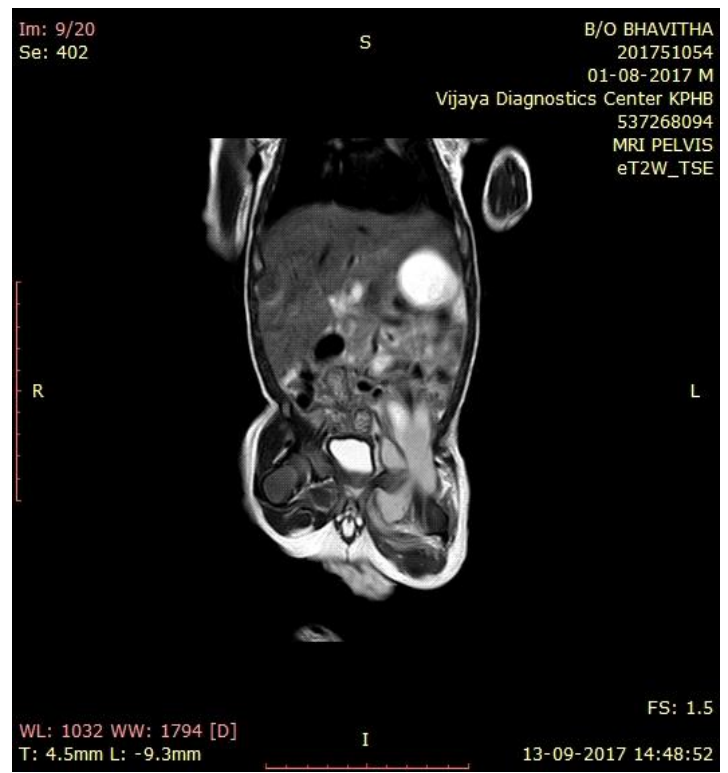

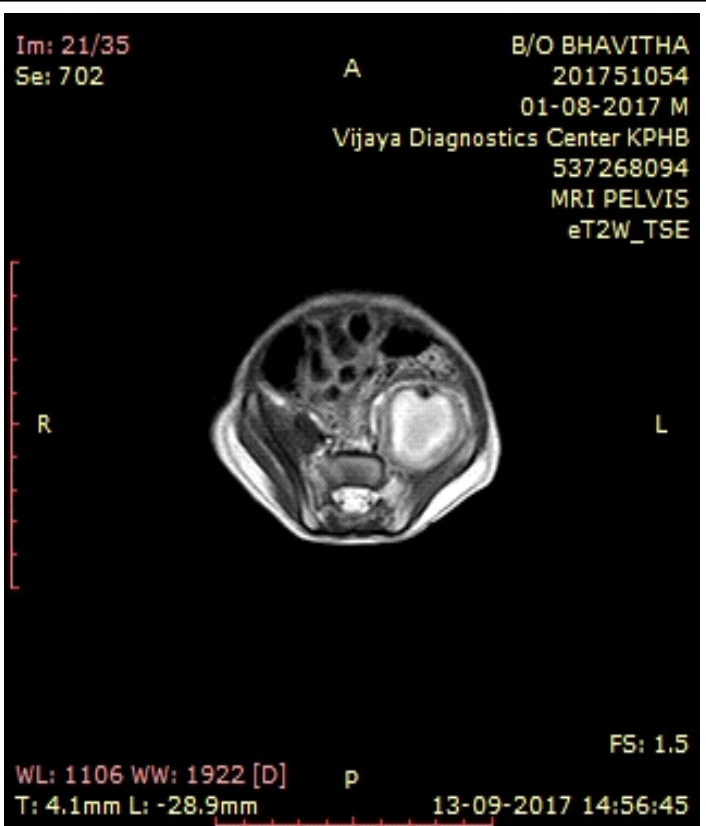

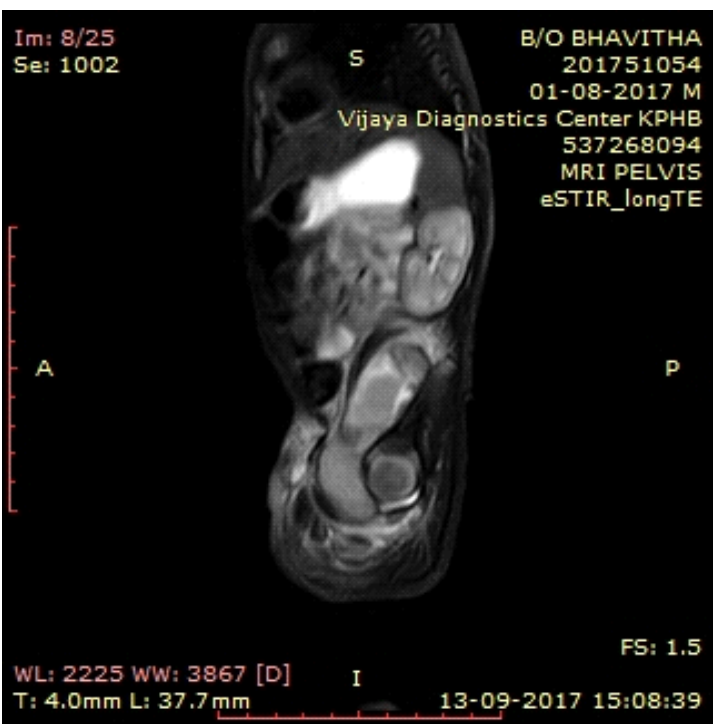

M.R.I Images Showing Hyper Intense Collection Involving Left Iliopsoas Muscle Extending Up to Proximal thigh Measuring Approximetly 7.1 X 3.4 X 2.7 Cms with Myofacial Edema of the Proximal thigh Muscles.

\section{Discussion}

Neonatal iliopsoas abscess is extremely rare as stated above, only 14 cases have been reported till date $(1 \& 2)$, This condition can turn lethal to a nenonate, They present with leg and groin swelling, limitation of movements in the joint associated with pain, in few cases may be associated with septic arthritis and spondylo discitis (3\&4) They are divided into Primary \& 
Secondary Iliopsoas abscess, Where in primary hemetogenous spread of occult site is noted. secondary spread of infection from spine (commonly in tuberculosis), sacro iliac joints, intestinal, renal or bone disease including appendicitis, inflammatory bowel disease, pyelonephritis, osteomyelitis can be observed. Possible differential diagnosis for this presentation includes septic arthritis of hip ${ }^{(5,6 \& 7)}$ cellulitis of thigh and abdominal wall ${ }^{(8)}$. when a neonate presents with thigh/inguinal swelling first septic arthritis, joint effusion must be ruled out and later psoas abscess must be suspected ${ }^{(9)}$.

Ultrasonography is the first choice of investigation, M.R.I is preffered choice of investigation as it has no ionising radiation \&, particularly safe for a female neonate. M.R.I helps in localising the extent of abscess \& bony involvement, surrounding soft tissue involvement and better deliniation for pre operative work up to perform drainage of the abscess.

Treatment includes antibiotic therapy and extra peritoneal surgical drainage ${ }^{(10)}$, Ultra sond guided drainage with strict aseptic conditions can be performed. Most common causitive organism for this condition is staphylococcus areus.

\section{Conclusion}

The prime motive to report this case is consider ilio psoas abscess as a differential diagnosis when a neonate presents with groin swelling, firstly rling out all the commener problems psoas abscess also should be ruled as this condition can be lethal to the child.

\section{References}

1. Vastyan AM, MacKinnon EA. Primary psoas abscess in a neonate. Am JPerinatol 2006;23:253e4

2. Journal of Pediatric Surgery Case Reports Volume 1, Issue 2, FEB 2013

3. Wang E, Ma L, Edmonds EW, Zhao Q, Zhang L, Ji S. Psoas abscess with associated septic arthritis of the hip in infants. J Paediatric Surg 2010; 45:2440-3.

4. Goyal A, Shah I. Infantile psoas abscess. Ann Acad Medic Singapore. 2013;42:415416.

5. Wang E, Ma L, Edmonds EW, Zhao Q, Zhang L, Ji S. Psoas abscess with associated septic arthritis of the hip in infants. J Pediatr Surg 2010;45:2440e3.

6. Okan F, Ince Z, Coban A, Can G. Neonatal psoas abscess simulating septicarthritis of the hip: a case report and review of the literature. Turk $\mathrm{J}$ Pediatr 2009;51:389e91.

7. Singer J. Neonatal psoas pyomyositis simulating pyarthrosis of the hip. Pediatr Emerg Care 1993;9:87e9.

8. Prassopoulos PK, Giannakopoulou CA, Apostolaki EG, Charoulakis NZ, Gourtsoyiannis NC. Primary ilio-psoas abscess extending to the thigh ina neonate: US, CT and MR findings. Pediatr Radiol 1998;28:605e7.

9. Okada Y, Yamataka A, Ogasawara Y, Matsubara K, Watanabe T, Lane GJ, et al.Ilio-psoas abscess caused by methicillinresistant Staphylococcus aureus(MRSA): a rare but potentially dangerous condition in neonates. Pediatr Surg Int 2004;20:73e4.

10. Dib M, Bedu A, Garel C, Mazda K, Philippe-Chomette $\mathrm{P}$, Rajguru $\mathrm{M}$, et al. Iliopsoasabscess in neonates: treatment by ultrasound-guided percutaneousdrainage. Pediatr Radiol 2000;30:677e80. 